\title{
Política de becas en el nivel medio superior mexicano: crítica a sus principios distributivos ${ }^{1}$
}

\author{
Jesús Aguilar-Nery
}

\section{RESUMEN}

El objetivo del estudio es analizar los principios que subyacen a la distribución de becas en el nivel medio superior en México, especialmente por género, por monto y por tipo. Se argumenta sobre la hipótesis de que han sido dos los principios que han guiado la política de becas: un enfoque de género reducido y equívoco que hace equivaler género con mujeres y un principio de distribución simplificado y contradictorio fincado sólo en dar un paliativo que mezcla asuntos de mérito y necesidad.

Palabras clave: perspectiva de género, nivel medio superior, justicia social, equidad educativa, México.

Jesús Aguilar-Nery

janery@unam.mx

Mexicano. Doctor en Ciencias, especialidad en investigaciones educativas, Instituto Politécnico Nacional-CINVESTAV, México. Investigador Titular A, definitivo, tiempo completo del Instituto de Investigaciones sobre la Universidad y la Educación (IISUE), Universidad Nacional Autónoma de México (UNAM). Temas de investigación: desigualdades escolares, política educativa en nivel medio superior, educación y justicia social.

\footnotetext{
${ }^{1}$ Este trabajo contó con recursos del Programa UNAM-DGAPA-PAPIIT-IN401616, bajo la responsabilidad del autor. Una versión previa de este texto aparecerá en el libro colectivo Educación y justicia. Editado por el Centro de Estudios Constitucionales del Tribunal Constitucional del Perú, bajo la coordinación de la Magistrada Marianella Ledesma Narváez.
} 


\section{Política de bolsas no nível médio-superior mexicano: crítica a seus princípios de distribuição}

\section{RESUMO}

O objetivo do estudo é analisar os princípios que sustentam a distribuição de bolsas de estudo no nível médio-superior no México, especialmente por gênero, por custo e por tipo. Se argumenta sobre a hipótese de que têm sido dois os princípios que têm guiado a política de bolsas: um enfoque de gênero reduzido e equívoco que faz equivaler gênero com mulheres e um princípio de distribuição simplificado e contraditório fundado só em dar um paliativo que mistura assuntos de mérito e necessidade.

Palavras chave: perspectiva e gênero, nível médio-superior, justiça social, equidade educativa, México.

\section{Scholarship Policy at the Mexican High School Level: a Critique of its Distributive Principles}

\section{ABSTRACT}

The purpose of this study is to analyze the principles underlying the distribution of scholarships at higher secondary level in Mexico, especially by gender, by amount and by type. The hypothesis is that two principles have oriented the scholarship policy: a reduced and equivocal gender approach that equates gender with women and a simplified and contradictory distribution principle based only on a palliative approach that mixes merit and need.

Key words: gender, perspective, high school, social justice, educational equity, Mexico. 


\section{Introducción}

Cada año se reportan incrementos en el número de becas otorgadas por los gobiernos en turno. Tan sólo en el VI y último informe del presidente Peña se anota que el $29.5 \%$ de estudiantes de escuelas públicas del sistema educativo mexicano tuvieron una beca, equivalente a 7.5 millones en el ciclo 2017-2018 (Presidencia de la república, 2018: 301), de ellas 1.9 millones se estimaban para la secundaria alta (nivel 3 de la Clasificación Internacional Normalizada de la Educación de la UNESCO) nivel medio superior (NMS); número que se contrasta positivamente con la cifra de 1.4 millones de becas del ciclo escolar 20122013, al inicio del sexenio presidencial (ibid.: 348).

En ese sentido, a pesar de las "cifras felices" presentadas en los informes oficiales, al mismo tiempo se tiene la impresión de que no son suficientes; ante todo al considerar que casi la mitad de la población nacional vive en condiciones de pobreza. Según datos del Consejo Nacional de Evaluación de la Política de Desarrollo Social (Coneval), en 2008 el 44\% de la población mexicana se encontraba en la categoría de pobreza (49.5 millones). Esto apenas bajó un punto porcentual ocho años después, pero aumentó en números absolutos; es decir, en 2016 43.6\% del total de la población era considerada pobre, equivalente a 53.4 millones de personas y de éstos casi $10 \mathrm{mi}-$ llones $(7.6 \%)$ se consideraba en pobreza extrema. ${ }^{2}$ Asimismo, datos reportados por UNICEF-México, en su informe 2017, bordean un panorama gris para niñas/os y adolescentes, ya que 1 de cada 2 se ubicó en situación de pobreza y 2 de cada 10 en pobreza extrema (UNICEF, 2017: 4). Dichas proporciones no han variado, ya que la misma fuente en 2012 reportaba que $53.8 \%$ de la población de 0 a 17 años (21.2 millones) se encontraba en situación de pobreza; más aún, en ese mismo año, "4.7 millones de niñas, niños y adolescentes (12.1\%) se encontraban en situación de pobreza extrema" (UNICEF, 2015: 42).
En México, los programas gubernamentales de becas han sido punta de lanza de las políticas para combatir las desigualdades educacionales y prácticamente en las últimas dos décadas se han convertido en la principal herramienta para enfrentarlas en todos los niveles escolares (Cuellar, 2013; Martínez y Martínez, 2013; Ordorika, 2015; OCDE, 2017). Sin embargo, hay elementos para pensar que se ha sobreestimado su potencial, porque reducen el espectro de las desigualdades escolares; es decir, las becas, si bien favorecen el acceso y hasta cierto punto la asistencia de niñas/os y jóvenes a las escuelas, especialmente de quienes viven en comunidades rurales o zonas marginadas, no son suficientes para cubrir los costos de oportunidad (Banco Mundial (BM), 2013), tampoco para mejorar sus aprendizajes y menos para garantizar que éstos sean pertinentes y de buena calidad como parece suponerse con dichos programas. En otros términos, la desigualdad no es una; lo que hay son múltiples facetas que se producen y reproducen, dentro y fuera de las escuelas.

Asimismo, en las escuelas del NMS hay peculiaridades, especialmente en relación con los trayectos escolares de mujeres y hombres que lo hacen distinto al resto de niveles, presentándose algunas inconsistencias en la distribución de las becas y sesgos que merecen discutirse. En este trabajo se exploran un par de hipótesis que explican las inconsistencias entre los datos oficiales y los principios que subyacen a la distribución de becas en el NMS.

Por una parte, se trata de mostrar que no se está siguiendo un enfoque de género, a pesar de que explícitamente se afirme que sí. En el mejor de los casos se está instrumentando una acción afirmativa hacia las mujeres, esto hace equivaler dar más apoyos a las mujeres como equidad de género cuando la mayoría de los datos no lo justifica. Por otra parte, se describe una concepción estrecha y contradictoria en el diseño de la distribución de los recursos, ya que mezcla

\footnotetext{
${ }^{2}$ Datos obtenidos de su sitio web: https://www.coneval.org.mx/Medicion/Paginas/Pobreza_2008-2016.aspx.
} 
elementos de compensación y mérito al momento de reconocer diferentes poblaciones; es decir, subyacen principios de justicia erráticos que sólo muy recientemente parecen ir resultando adecuados, pero en frecuente tensión.

El trabajo se compone de las siguientes secciones. En primer lugar, se describe sintéticamente el emplazamiento teórico-metodológico, para después hacer un alto en los antecedentes de la distribución de las becas en el ámbito nacional en el NMS. Enseguida se presentan ciertos datos relacionados con el trayecto escolar del nivel abordado, para observar las tendencias que marcan el trayecto escolar de los y las jóvenes. Después se presenta la política de distribución de becas en el NMS y se discuten algunas de sus implicaciones. Finalmente, se concluye con una serie de reflexiones del estudio presentado y la necesidad de realizar ajustes para establecer una política de becas justa.

\section{Encuadre teórico-metodológico}

En este trabajo se asume una postura a favor de la justicia social en el campo educativo. De acuerdo con la acertada síntesis del grupo académico español encabezado por Javier Murillo, la justicia social es un concepto dinámico con una carga política fuerte, ya que implica cierta visión sobre un mundo mejor posible. Siguiendo a los investigadores españoles (quienes, a su vez, se apoyan en Griffiths) se sugiere pensar la justicia social como un verbo: "es decir, un proyecto dinámico, nunca completo, acabado o alcanzado una vez y para todos: siempre debe estar sujeto a reflexión y mejora" (Murillo et al., 2011: 9).

Retomando a los autores principales de la teoría social y la filosofía política anglosajona que han debatido sobre el concepto citado en el último medio siglo, se ha llegado a precisar que tres conceptos lo fundamentan: distribución, reconocimiento y participación.

El primero está centrado en la distribución de bienes, recursos materiales y culturales; el segundo en el reconocimiento y el respeto social y cultural de todas y cada una de las personas, en la existencia de unas relaciones justas dentro de la sociedad; el tercero está referido a la participación en decisiones que afectan a sus propias vidas, es decir, asegurar que las personas son capaces de tener una activa y equitativa participación en la sociedad (Murillo et al., 2011: 9).

Tales conceptos son interdependientes y funcionan también como principios que deberían orientar las acciones de justicia o de gobierno. Así, por ejemplo, la justicia económica está normalmente asociada con una (re)distribución de bienes, pero esta asociación no es exclusiva, sino que se intersecta con otros rasgos culturales como la etnia, el género, etcétera, u otras dimensiones que dan pie al clasismo, racismo y sexismo que implican tanto problemas o injusticias materiales como de negación de reconocimiento social. Por lo tanto, la triada conceptual de la justicia social debe procurar mantenerse unida, al menos desde el punto de vista teórico.

Ahora bien, los autores citados construyen un interesante puente normativo entre la justicia social y su aterrizaje con el campo educativo, a partir de tres principios. Cito:

1) Calidad alta y distribución equitativa. Una educación pertinente, relevante en objetivos para todos, pero donde dedique más esfuerzo y recursos en quienes por origen, cultura, lengua materna o capacidades necesitan más.

2) Reconocimiento e identidad. Una educación que no sólo establece condiciones, sino que promueve el reconocimiento, el respeto y la valoración de las diferencias individuales, sociales y culturales de los y las estudiantes; además de considerar su relación con las desigualdades de diversos tipos.

3) Plena participación. Una educación que fomente y asegure no sólo el aprendizaje, sino la participación de todos y todas en un ambiente de libertad y sana convivencia (Murillo et al., 201 1: 11). 
La narrativa triádica de compresión de la justicia que combina redistribución de recursos materiales, humanos y simbólicos, partiendo del reconocimiento de las diferencias de personas y grupos, así como de contextos de necesidad y de capacidades en una arena política de representación paritaria, se propone como un marco para volver a discutir las políticas escolares y educativas, así como las alternativas que pueden derivarse para mejorar las escuelas y los sistemas educativos con el propósito de explorar sus alcances para construir sociedades más justas.

Aunque no se hizo explícito en el diseño del programa de becas en el NMS, al menos al inicio, de hecho, se introdujo una distribución diferenciada por "sexo/género", por lo cual es menester anotar la postura desde la cual se aborda. De acuerdo con Messina (2001:13), el concepto de género ha sido una herramienta de denuncia sobre convertir la diferencia cultural entre los sexos en desigualdad y ha contribuido a clarificar las relaciones de poder. Si bien históricamente las construcciones sociales de la femeneidad y la masculinidad han sido y son exigentes y opresivas para mujeres y hombres, particularmente ha sido documentado cómo las mujeres han ocupado en muchos espacios sociales el lugar de subordinadas. Como ha señalado Bourdieu (2000), la dominación masculina se monta en cierta "naturalización" de un patrón institucionalizado de valor cultural que ha privilegiado y sigue privilegiando los rasgos asociados con la masculinidad, al mismo tiempo que devalúa lo codificado con lo femenino. De hecho, esa inercia es la que subyace a la definición de las primeras instituciones y políticas públicas mexicanas con "perspectiva de género", tal es el caso del Instituto Nacional de la Mujeres (Inmujeres) creado en 2001. No obstante, subrayo que el género es "tanto una categoría relacional como una categoría política" (Messina, 2001: 13) y que las desigualdades marcan y pueden ser opresivas tanto para hombres y mujeres como para otros géneros.

La construcción social de los géneros es un proceso complejo y es necesario sistematizar algunos de los puntos oscuros y varias de las confusiones que está originando la categoría de género, producto de su mayor divulgación en los últimos años, que ha redundado en un uso más libre pero menos riguroso, identificándose con frecuencia exclusivamente con lo femenino, las mujeres y los movimientos feministas; por lo que importantes especialistas han advertido el equívoco de que ciertos "estudios de género" a menudo significan estudios de mujeres, pero no de hombres u otros géneros (Feijoó, 2013: 12; Messina, 2001: 13; De Barbieri, 1995: 47).

Sabemos que la categoría de género se institucionalizó como parte de la corriente académica internacional entre los años setenta y ochenta del siglo XX en las ciencias sociales (Lamas, 1996) y se hizo visible en los organismos educacionales internacionales a partir de la década de los noventa, sobre todo mediante la reunión de Jomtien, Tailandia, en 1990, para aterrizar en las políticas educativas nacionales durante la siguiente década. En México, su aparición conceptual se remite a 2001 en la Constitución y hasta 2009 se incluye en la Ley General de Educación, en el apartado III sobre la equidad (artículos 32 y 33), así como en el apartado IV sobre el proceso educativo (artículo 41).

Con las dos vertientes teóricas sintéticamente trazadas se propone un análisis de los datos del trayecto escolar y las normas establecidas para la distribución de becas en el NMS, mediante dos programas federales, los de mayor cobertura, sin dejar de reconocer que hay otros programas o mecanismos tanto públicos como privados que brindan apoyos de ese tipo. ${ }^{3}$ Para nuestro análisis se presentan, de modo acumulado y hasta donde lo permiten las fuentes,

\footnotetext{
${ }^{3}$ Baste mencionar el programa "Prepa Sí" del gobierno de la Ciudad de México, que data de 2007; y el "Bécalos", auspiciado por la Asociación de Bancos de México, Fundación Televisa y los bancos más importantes del país, según se anuncia en su portal Web, cuyos antecedentes se remontan a 2006. Véase https://becalos.mx/transparencia-y-resultados/
} 
las principales cifras oficiales del trayecto escolar del NMS difundidas por la Secretaria de Educación pública (SEP) y el Instituto Nacional para la Evaluación de la Educación (INEE), principalmente índices como absorción, abandono, egreso, entre otros, para luego contrastarlas con las pautas de distribución de las becas: por sexo, modalidad de becas y montos.

\section{Antecedentes de la política de becas en el nivel superior mexicano}

El programa de becas en efectivo data de los años cuarenta del siglo XX (Diario Oficial de la Federación (DOF), 2003). Desde entonces la variable socioeconómica fue dominante, pero entonces también se mezcló con el mérito. En aquella época, las becas: "además de un estímulo para los estudiosos, eran un medio para que los elementos sociales de capacidad económicamente débil pudieran llevar a cabo estudios que por sí mismos no podrían realizar" (DOF, 2003: 5).

Posteriormente, con la puesta en marcha del Programa de Educación, Salud y Alimentación - Progresa - en 1998, se incluyó una nueva variable para la distribución de becas en los niveles de primaria y secundaria: el sexo. Se justificó de esta manera: "tiene el propósito de estimular el que los jóvenes sigan estudiando hasta concluir el ciclo de educación básica, y con ello evitar la deserción prematura causada por las necesidades de incorporarse a un empleo a temprana edad o de realizar las labores domésticas en el caso de las niñas" (Progresa, 1998: 41).

Lo anterior se observa también en los documentos de política educativa más importantes de la última década, como son los planes de educación, donde la perspectiva de género se trata como un recurso evocativo, en cierto modo transversal a las políticas, pero que no guarda coherencia con el presupuesto, ni con los indicadores de seguimiento ni de resultados. De acuerdo con Barajas (2006: 54), al no tener el carácter de un objetivo (general o específico), "entonces, las dependencias responsables no están obligadas a diseñar acciones o asignar presupuesto específicamente para tal fin".

Sin embargo, en las reglas de operación (RO) del Progresa del 1999 encontramos tal vez la que sea la justificación más explícita sobre la que se establece la distribución de becas con "perspectiva de género". Entonces se decía que "casi siempre" las desigualdades son mayores para las mujeres, esto "las vuelve más vulnerables a condiciones de pobreza y minan sus esfuerzos por mejorar su situación personal y la de sus hijos". Por tal razón "Progresa promueve la igualdad de género y busca elevar la participación de las mujeres para que cuenten con oportunidades auténticamente igualitarias para su pleno desarrollo personal" (DOF, 1999: 6). Enseguida se justifica que se otorgan los distintos apoyos a través de las madres de familia, "por su compromiso y responsabilidad para hacer el mejor uso de estos apoyos". De inmediato se agrega que debido a que "con frecuencia" las niñas interrumpen más tempranamente su escolarización que los varones, por tal razón la becas del Progresa "son ligeramente más elevadas para las niñas que para los niños a partir de los estudios de secundaria" (DOF, 1999: 6). Estas últimas afirmaciones no se cumplen para NMS.

Por su parte, en 1999 la Dirección General de Acreditación, Incorporación y Revalidación (DGAIR) conservó la operación del programa de becas para los niveles medio y superior tecnológica, y en 2002 la DGAIR reorientó dicho programa para denominarlo: "Programa de Becas a la Excelencia Académica y al Aprovechamiento Escolar". Según esto porque se consideró suficiente el impacto de programas como Oportunidades (antes Progresa) y Pronabes, y se advirtió "la necesidad de reconocer a los educandos más destacados y la pertinencia de promover la calidad educativa y el aprovechamiento escolar" (DOF, 2003:6). Con dicho programa se amplió el horizonte de los fundamentos de distribución de los apoyos en efectivo, porque introdujeron nuevas variables como el reconocimiento de ciertos 
grupos vulnerables o vulnerabilizados: las personas que viven con alguna discapacidad, indígenas o madres adolescentes, etcétera, pero también introdujo un énfasis en el reconocimiento del desempeño estudiantil e incluso la "excelencia"; en otras palabras, se hizo más evidente cierta tensión entre principios (re) distributivos y de reconocimiento de las diferencias, vistos de modo mutuamente excluyente, más que en sus respectivos cruces.

\section{Indicadores tradicionales del trayecto escolar por variable de sexo/género en el NMS}

Las desigualdades entre hombres y mujeres en el nivel medio superior rompen con el patrón del nivel básico en la mayoría de los indicadores tradicionales, salvo en la tasa de absorción, la cual permite conocer el porcentaje de población que finalizó un nivel educativo y se incorpora al siguiente. Este indicador es probable que vea afectada su medición por la presencia de alumnos de cambios de modalidad, de jurisdicción e incluso de país, o debido a las reinserciones de jóvenes provenientes de generaciones anteriores. Esta situación se refleja en valores superiores a $100 \%$ (ver gráfica 1$)$.

Así, se observa la tendencia que la tasa de absorción en el NMS fue desigual para las mujeres; a pesar de que el egreso de la secundaria baja es mayor para las chicas. Cabe precisar en números absolutos las diferencias en el alumnado de nuevo ingreso al NMS, ya que ha sido más o menos fluctuante, pues la menor diferencia se dio en el ciclo 2010/2011 (alrededor de 11 mil varones más), mientras en el ciclo 2013/2014 se dio la mayor, cuando ingresaron 41556 más hombres que mujeres; el promedio de los siete ciclos disponibles indica 26911 más de hombres por año al inicio del ciclo escolar correspondiente (ver gráfica 2). Esto seguramente es el argumento principal para el otorgamiento de becas en dicho nivel favorable a las mujeres, aunque en el resto del trayecto las desigualdades claramente son desfavorables para los varones, como lo veremos enseguida.

\section{Gráfica 1. Tasa de absorción nacional NMS por sexo, 2008/2009-2015/2016}

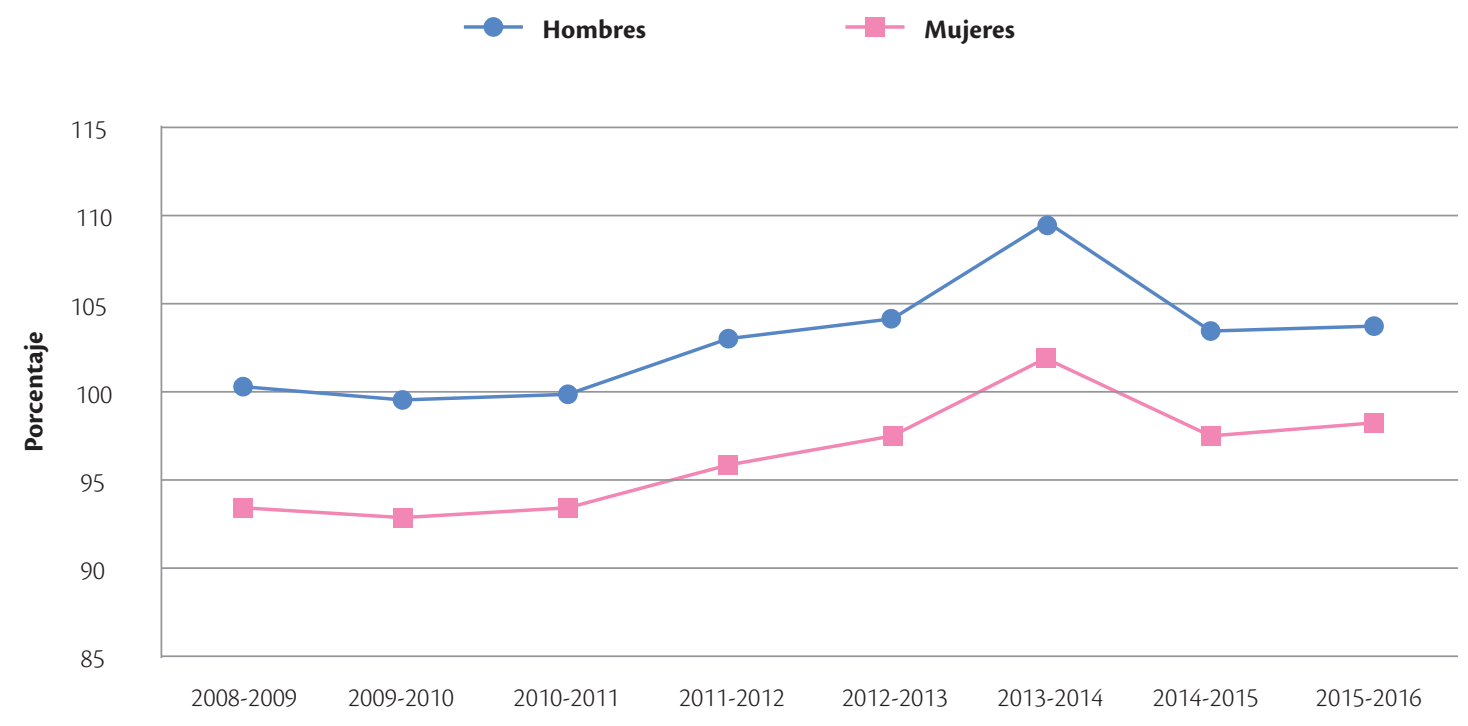

Año 
Gráfica 2. Estudiantes de nuevo ingreso nMS nacional por sexo, ciclos 2008/2009-2015/2016

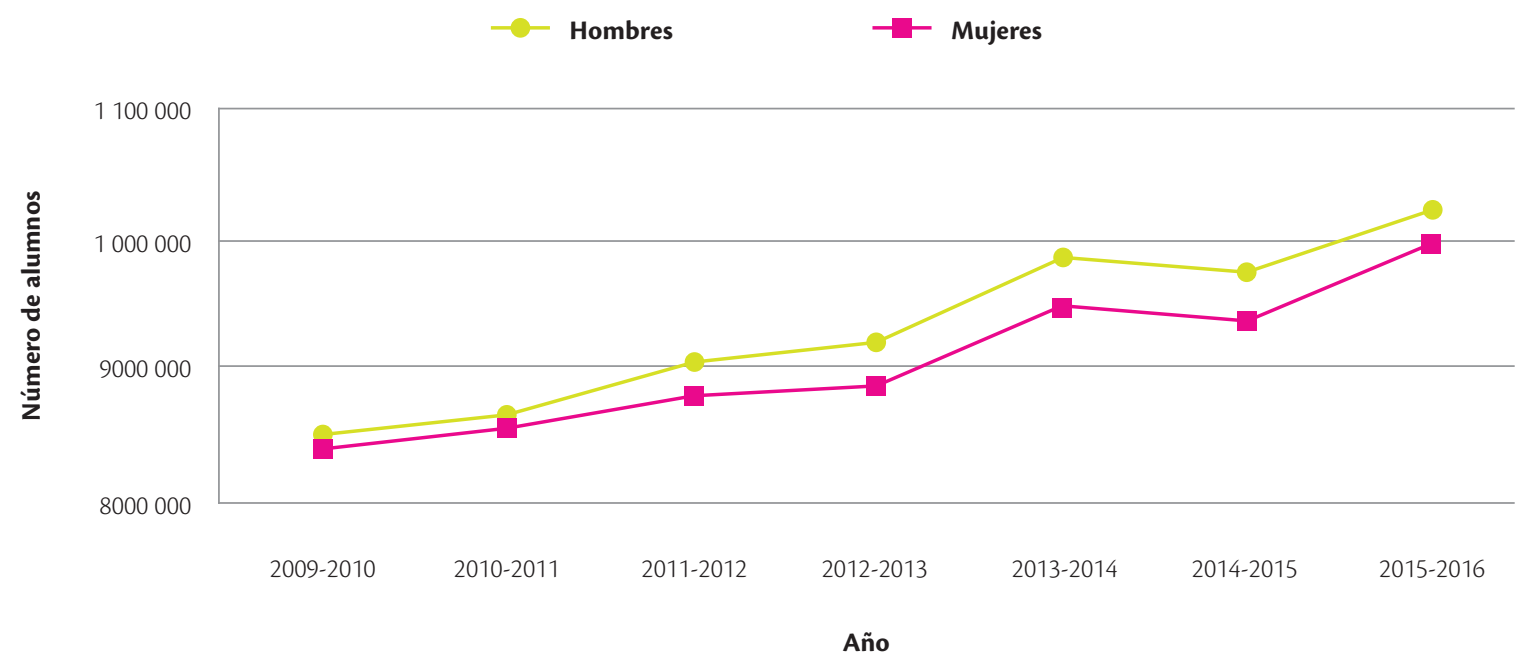

Fuente: Banco de Indicadores INEE, Tablas ATO4a.

La desigualdad entre hombres y mujeres en la matrícula y la cobertura escolarizada del NMS en México ha seguido un claro cambio de tendencia en las dos últimas décadas. Durante los años noventa, hasta el ciclo 1997-1998, las mujeres estaban en ligera desventaja, a partir de entonces se observa que la asimetría se desplaza hacia los varones, durante más de 15 años, como se observa en las gráficas 3 y 4 . Si bien la brecha que se abrió en 2001/2002 a favor de ellas se redujo en el ciclo 2012/2013, en los dos últimos ciclos se volvió a abrir, por lo que más mujeres asisten a las escuelas que los varones.

Gráfica 3. Matrícula escolarizada nacional, por sexo NMS 1994-2017

Hombres

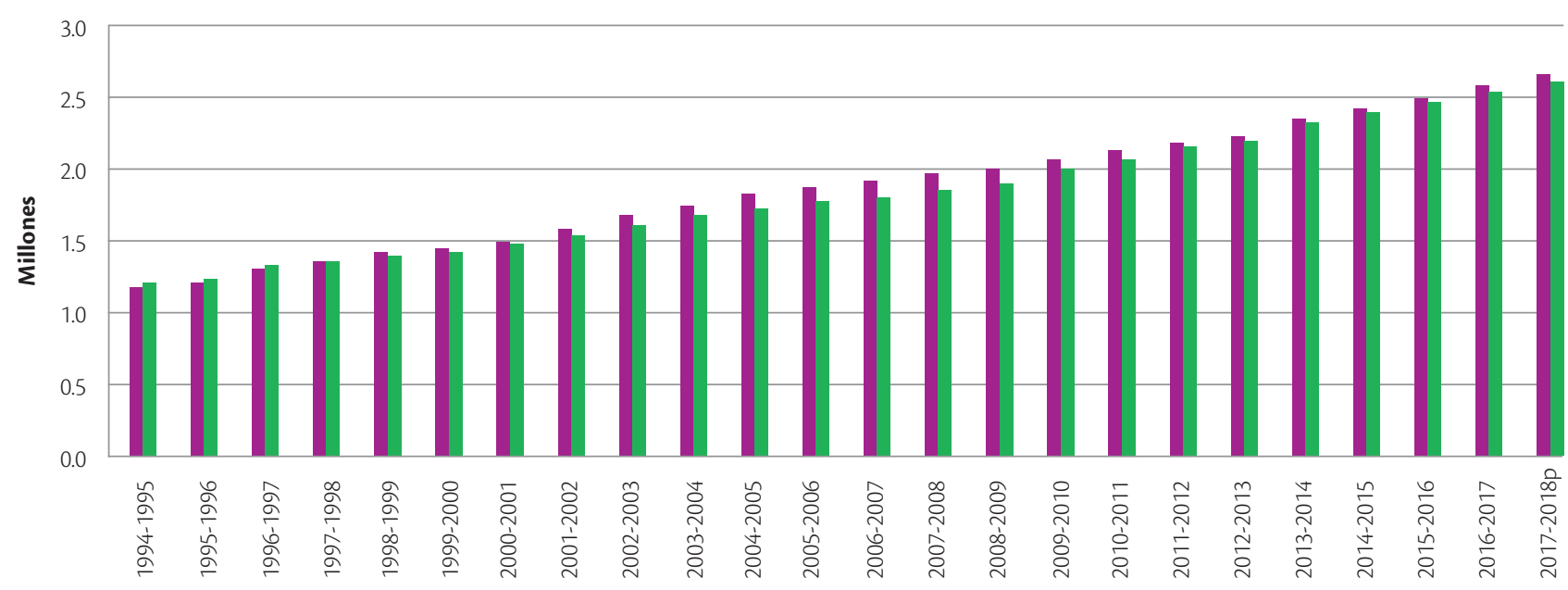

Año 
$\mathrm{El}$ indicador anterior se complementa con el de tasa bruta, el cual indica el número de estudiantes matriculados al inicio del ciclo escolar, por cada 100 individuos. Para el NMS se considera la modalidad escolarizada y la población de 15 a 17 años, es decir, la edad típica; como se observa en la gráfica 4, se mantiene un comportamiento semejante a la matrícula, que considera todas las edades. Incluso señalamos que las metas del sexenio de Enrique Peña no se cumplieron en este indicador, pues se propuso para 2018 que los varones alcanzaran un 79\% y las mujeres un $81.1 \%$; pero las estimaciones son que llegarán a $76.4 \%$ ellos y $80.7 \%$ ellas.

\section{Gráfica 4. Tasa bruta de escolarización por sexo NMS (15-17 años) nacional 1997-2017}

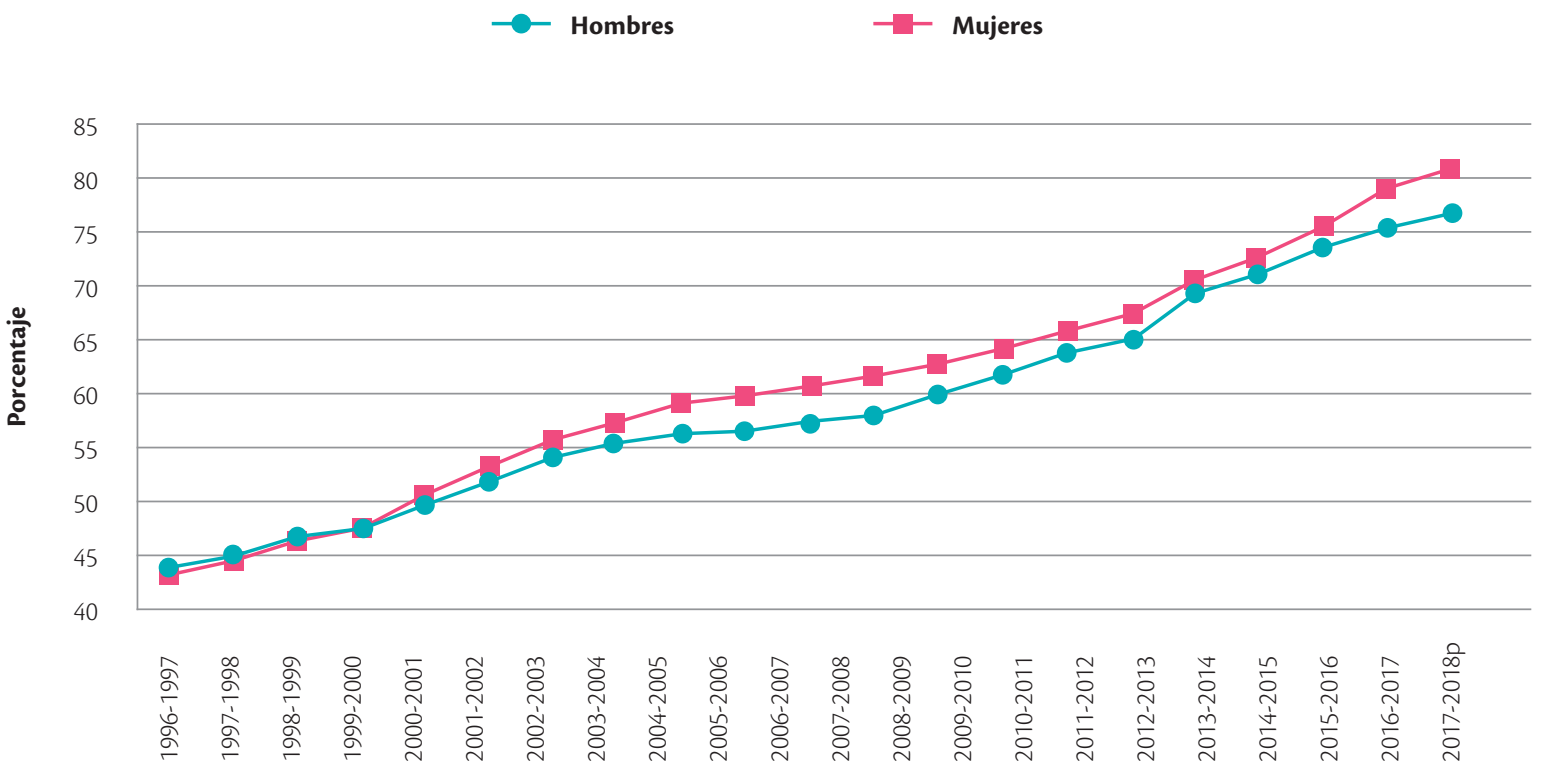

Año

Fuente: Presidencia de la República, 2018.Anexo estadístico del 60 Informe de Gobierno.. p = preliminar

No sólo en la matricula los varones del NMS han venido disminuyendo en proporción, sino que en el resto del trayecto escolar se reconocen desigualdades que afectan su permanencia y su egreso. La tasa de aprobación, tanto al final de los cursos como luego del periodo de regularización (fechada hasta el 30 de septiembre de cada año), es desfavorable a los varones entre 5 y 10 puntos respecto a las mujeres (véase gráfica 5).

En correspondencia con mayores tasas de aprobación de las mujeres, ellas presentan menores porcentajes de extraedad grave en el NMS, esto es, aquellos estudiantes que se han desfasado por dos años o más entre su edad cronológica y la edad escolar típica para cursar cierto nivel. Según datos del INEE, aproximadamente $12.5 \%$ de mujeres y $16 \%$ de varones han presentado extraedad grave, en promedio, en los últimos cinco años. Además, se destaca que la extraedad es desigual en todos los grados para los hombres, especialmente marcada en primer grado y luego va disminuyendo un poco. En todo caso, el estudiantado con extraedad grave está en mayor riesgo de interrumpir sus estudios. 
Gráfica 5. Tasa de aprobación NMS a fin de cursos y después del periodo de regularización por sexo 2008/2009-2014/2015

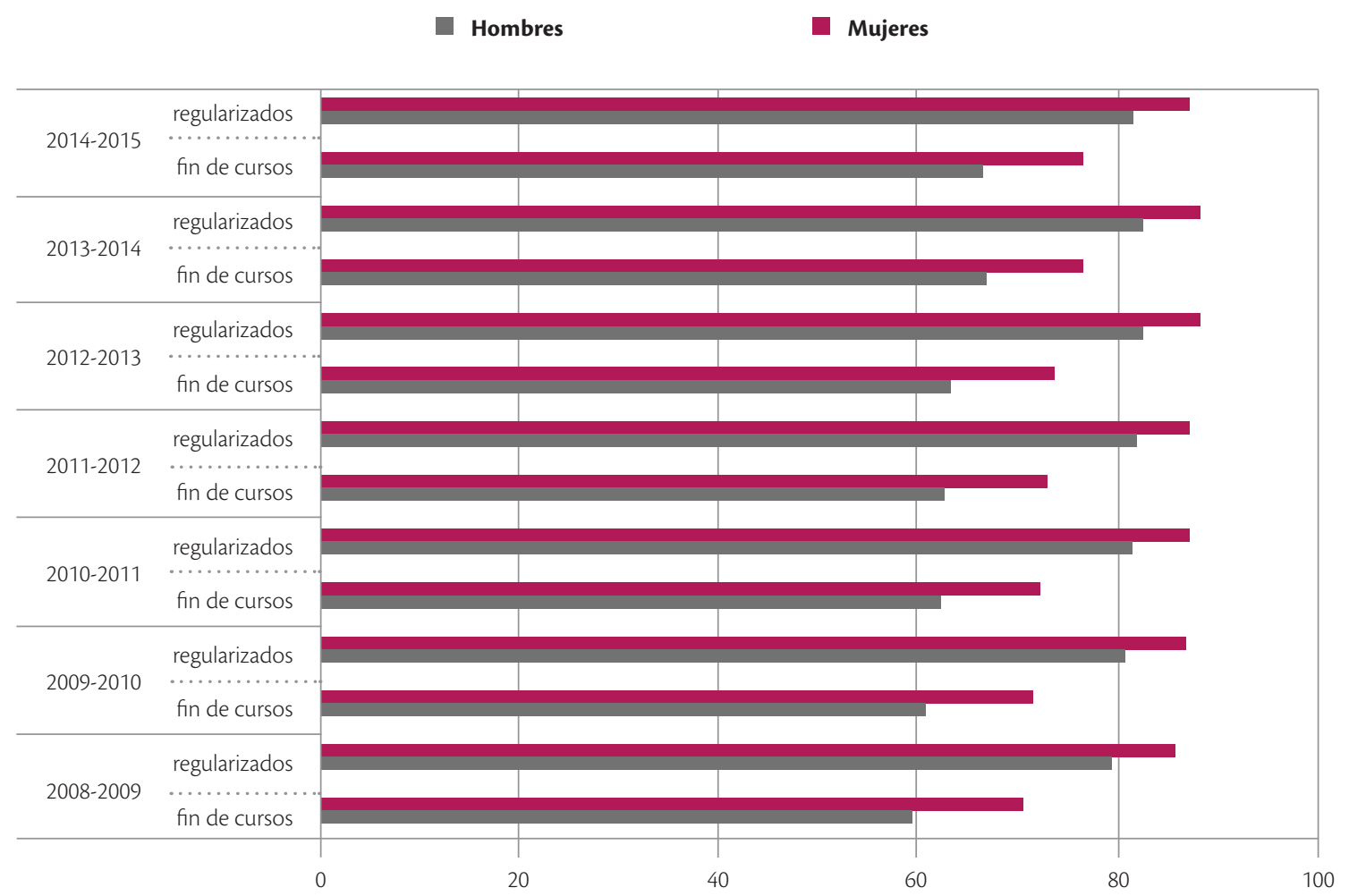

Fuente: Banco de indicadores INEE, Tablas ATO2b

Gráfica 6. Porcentaje de estudiantes con extraedad grave NMS por sexo y grado escolar 2011/2012-2015/2016

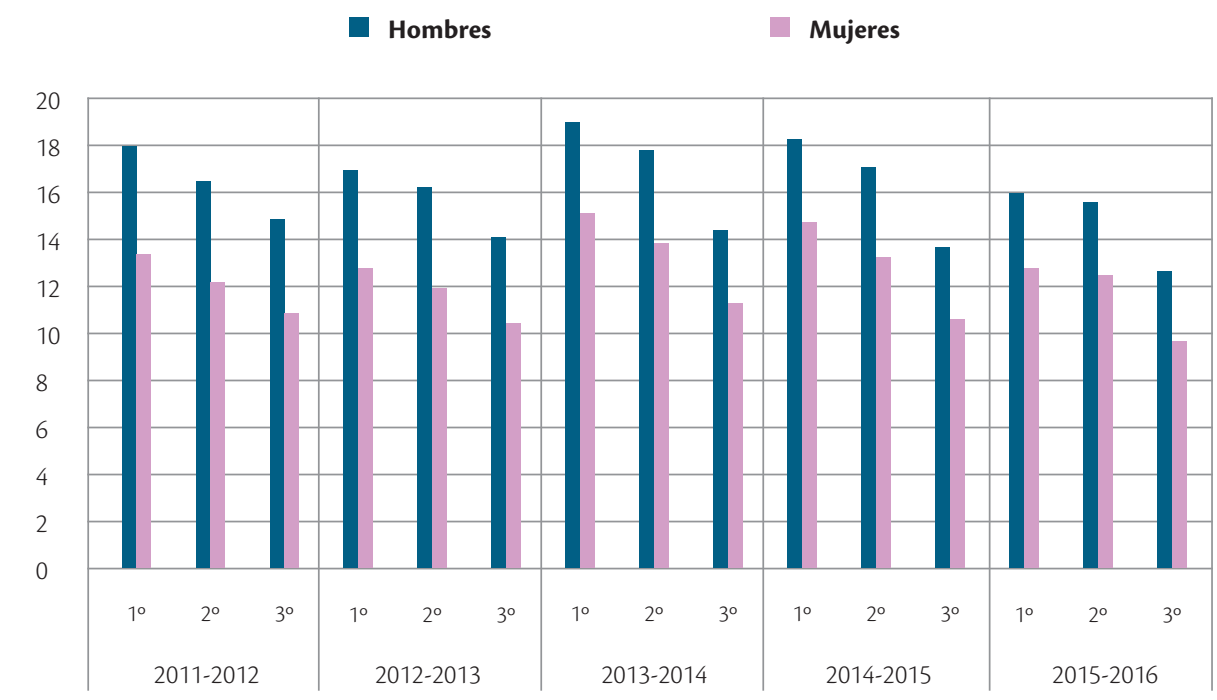


Los datos también muestran un mayor abandono varonil que femenil de modo consistente durante prácticamente las últimas dos décadas. Si bien se cerró un poco la brecha en los últimos seis ciclos escolares, mantiene una distancia de poco más de cuatro puntos a favor de las chicas. El dato más reciente es de $15.9 \%$ para ellos y $11 \%$ para ellas.

\section{Gráfica 7. Tasa de abandono por sexo, NMS nacional, 1997/1998-2016/2017}

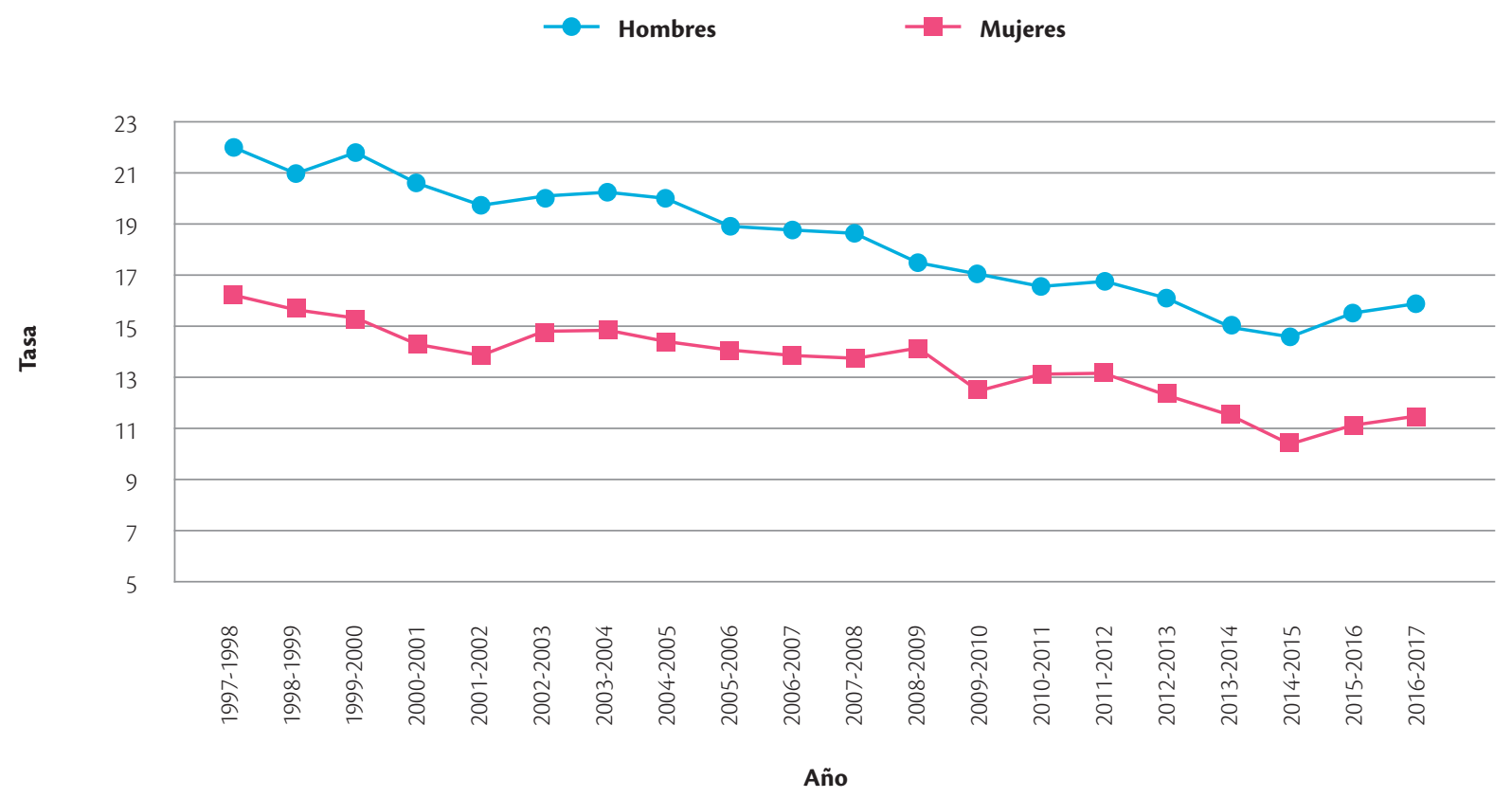

Fuente: Presidencia de la República, 2018. Anexo estadístico del $6^{\circ}$ Informe de Gobierno.

En cifras absolutas tenemos una idea más precisa de la magnitud de las díferencias de aquellos/as que abandonan la escuela. Datos de la SEP (SEMS y COPEEMS, 2012: 32) reportados en la Encuesta nacional de deserción apuntan que en la década 2000/2001 al 2010/2011 hubo marcados vaivenes. En el primer lustro rondó una brecha de 83 mil varones que dejaron las escuelas más que las jóvenes; los siguientes cuatro años hubo cierta mejora hasta llegar a poco más de 50 mil en el ciclo 2008/2009, el número más bajo en los años registrados. Luego de una fuerte reducción en el ciclo 2009/2010 volvió a crecer el margen en el último lustro hasta alcanzar, en el ciclo más reciente (2014/2015) la cota más alta en 14 años, cuando 103,235 mil varones abandonaron más que las mujeres (ver cuadro 1). En promedio,
79 mil varones por año en casi tres lustros. Un número de por sí enorme, que sigue creciendo año con año: más de 700 mil estudiantes en promedio en los dos últimos ciclos, por lo que es necesario redoblar esfuerzos para garantizar la permanencia de los y las jóvenes en las escuelas, consiguiendo además que su formación sea adecuada.

Finalmente, datos relacionados con la conclusión del NMS, específicamente el indicador de eficiencia terminal, según resultados de casi una década, se observa una pauta constante, claramente desigual para los varones: 8.5 puntos de diferencia en promedio en dicho periodo. En otras palabras, siete de cada 10 chicas concluyen en el tiempo deseable sus estudios de bachillerato mientras solo seis de cada 10 varones. (gráfica 8). 
Política de becas en el nivel medio superior mexicano: crítica a sus principios distributivos

Cuadro 1. Abandono de hombres y mujeres NMS, ciclos 2000/2001-2014/2015

\begin{tabular}{|c|c|c|c|c|}
\hline Ciclo & Hombres & Mujeres & Diferencia H/M & H+M \\
\hline $2000-2001$ & 295667 & 205853 & 89814 & 501520 \\
\hline $2001-2002$ & 304356 & 222432 & 81924 & 526788 \\
\hline $2002-2003$ & 324866 & 249861 & 75005 & 607209 \\
\hline $2003-2004$ & 345462 & 261747 & 83715 & 608500 \\
\hline $2004-2005$ & 347359 & 261141 & 76218 & 602336 \\
\hline $2005-2006$ & 337785 & 264551 & 73234 & 611184 \\
\hline $2006-2007$ & 342253 & 268931 & 73322 & 624684 \\
\hline $2007-2008$ & 347961 & 276723 & 50256 & 622830 \\
\hline $2008-2009$ & 336543 & 286287 & 94895 & 587567 \\
\hline $2009-2010$ & 341231 & 246336 & 60716 & 625142 \\
\hline $2010-2011$ & 342929 & 282213 & 73702 & 651074 \\
\hline $2011-2012$ & 362388 & 288686 & 86233 & 636237 \\
\hline $2012-2013$ & 361235 & 275002 & 103235 & 714975 \\
\hline $2013-2014$ & 398520 & 316455 & 294921 & 6953077 \\
\hline $2014-2015$ & 398156 & & \\
\hline
\end{tabular}

Fuente: adaptado de SEP 2012:30, con datos de la SEMS 2000-2010, para ciclos 2011-2014 Banco de indicadores INEE, Tablas AT02d.

Gráfica 8. Porcentaje de eficiencia terminal NMS por sexo, 2007/2008-2016/2017

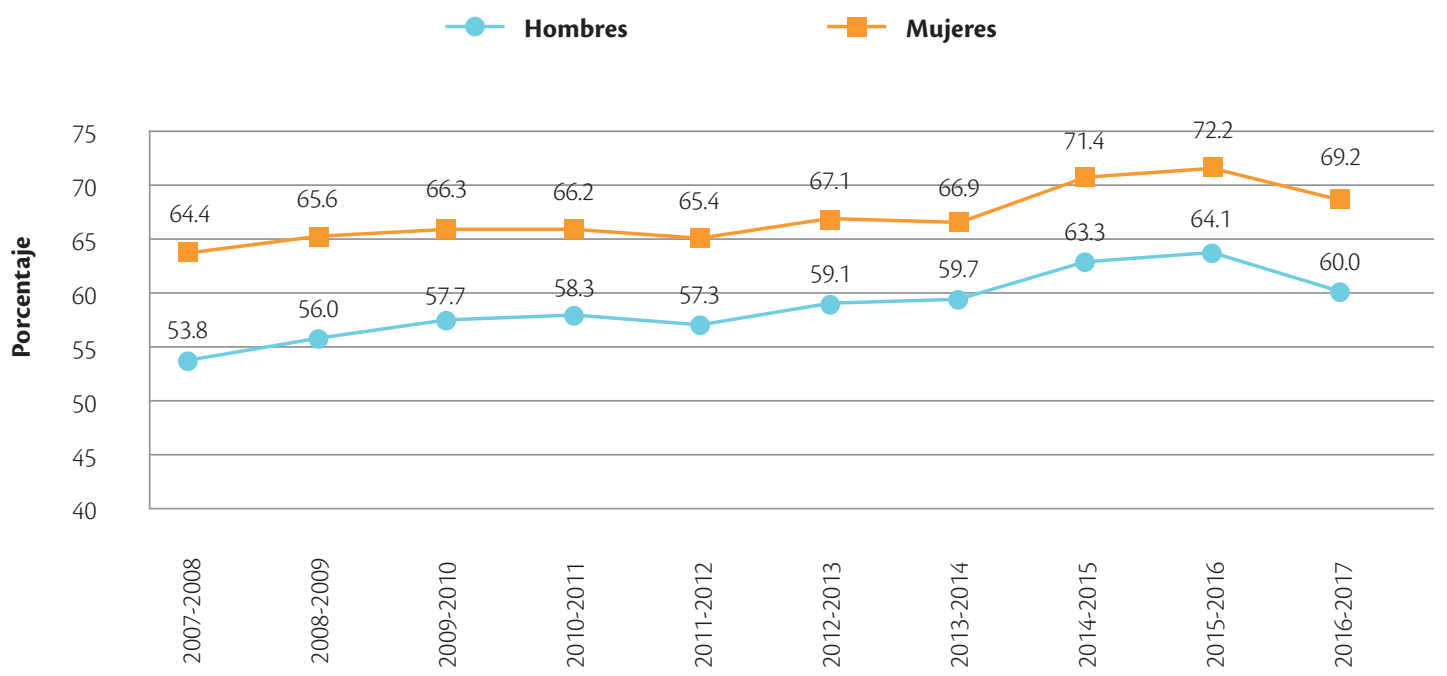

Año 
Si bien actualmente tenemos cifras que describen la trayectoria de hombres y mujeres en el NMS, todavía son insuficientes por sexo/género en cruce con otras variables que también impactan la permanencia y la consecución de aprendizajes significativos. Ocasionalmente se han recopilado por las instancias oficiales, por lo que vale la pena llamar la atención para que se sigan desglosando. Una variable que tiene fuerte impacto en el ámbito escolar es la socioeconómica, pero de la cual existen pocos datos sobre los/as jóvenes bachilleres. El INEE publicó hace algunos años cifras relacionadas con los niveles de ingresos (quintiles) y el sexo de jóvenes que asisten al NMS. Estos indicaban, para 2008, que el porcentaje de hombres del grupo de edad de 15 a 17 años, en casi todos quintiles, asistían menos que las mujeres, aunque no así en el quintil IV; mientras en el rango de edad entre 15 y 18 años, en el quintil I (el más bajo) era un poco mayor la asistencia de hombres que de mujeres, aunque en general la tendencia de la desigualdad es hacia una menor asistencia de los varones (ver cuadro 2).

\section{Cuadro 2. Porcentaje de población que asiste al NMS respecto de aquella atendible ${ }^{1}$ según quintil de ingreso neto per cápita, por grupos de edad y sexo (2008)}

\begin{tabular}{|c|c|c|c|c|}
\hline \multirow{2}{*}{ Quintil de ingresos } & \multicolumn{2}{|c|}{ Asiste a media superior } & \multicolumn{2}{|c|}{ Población joven atendible en media superior' } \\
\hline & 15-17 años & 15-18 años & 15-17 años & 15-18 años \\
\hline \multicolumn{5}{|c|}{ Hombres } \\
\hline I & 62.0 & 56.5 & 351716 & 429779 \\
\hline$\|$ & 68.5 & 63.9 & 487994 & 604361 \\
\hline III & 66.4 & 61.7 & 489711 & 622301 \\
\hline IV & $82.6^{*}$ & $72.2^{*}$ & 479954 & 650645 \\
\hline v & $89.7^{*}$ & $85.9^{*}$ & 439266 & 537961 \\
\hline Total & 74.2 & 68.3 & 2248641 & 2845047 \\
\hline \multicolumn{5}{|c|}{ Mujeres } \\
\hline । & 62.8 & 54.0 & 396408 & 495390 \\
\hline$\|$ & 70.7 & 64.1 & 514718 & 620324 \\
\hline III & 70.8 & 64.2 & 561171 & 684162 \\
\hline IV & $80.3^{*}$ & $74.3^{*}$ & 475764 & 590819 \\
\hline v & $92.1^{*}$ & $86.6^{*}$ & 399710 & 467956 \\
\hline Total & 75.0 & 68.2 & 2347771 & 2858651 \\
\hline
\end{tabular}

1 La población atendible en media superior refiere a aquélla con educación básica y sin media superior.

* Diferencias estadísticamente significativas del quintil de ingresos previo (diferencia a 95\% de confianza).

Fuente: Banco de Indicadores Educativos, tabla CSO5b-1. 
Se debe reconocer que la mayoría de los datos presentados marcan desventajas para los jóvenes, pero el panorama es más complicado porque hay otros indicadores que marcan desigualdades para las mujeres. Por ejemplo, datos del INEE señalan que el porcentaje de quienes no estudiaban ni trabajaban en 2008 era desigual para ellas, siendo más marcado en el grupo de edad de 15 a 18 años (versus el de 15 a 17), donde la diferencia casi se duplicó (11.1\% varones vs 21.7\% mujeres). Datos más recientes indican una tendencia semejante: las jóvenes que no tienen empleo, ni capacitación, así como las que son madres, encuentran grandes barreras para formar parte de la fuerza de trabajo en México. Las jóvenes mexicanas de entre 15 y 29 años tienen casi cuatro veces más probabilidades de estar sin empleo o sin escolarización o capacitación que los varones, situación que perjudica su condición económica presente y las perspectivas de trabajo futuras (OCDE, 2017:32, traducción propia). Algo semejante, sucede con datos relacionados con el lugar de residencia o la condición étnica, que marcan desigualdades para ellas, aunque no se tienen datos desglosados por sexo/género, sólo globales. ${ }^{4}$

En breve, no se debe concluir de los datos citados que deban restarles apoyos a las mujeres para beneficiar a los varones, ni se desconocen los efectos positivos de los apoyos que reciben y administran las mujeres, pues éstos impactan a su núcleo familiar del que son dependientes, pero también del que formen a futuro. Lo que se afirma es el deber de combinar necesidades con el reconocimiento de diferencias en el trayecto escolar, contextos geográficos, étnicos, entre otras variables para hacer una distribución justa.

\section{Política de becas en el NMS: del sesgo de género al reconocimiento (parcial) de las diferencias}

Con la puesta en marcha del Programa de Alimentación, Salud y Educación (Progresa) en 1997, programa estelar del sexenio 1994-2000, el cual estuvo dirigido especialmente a las zonas rurales de pobreza extrema, encontramos el principal antecedente del programa de becas en el NMS. ${ }^{5}$

El Progresa y sus sucesores, conocidos como "programas de transferencia condicionada", proliferaron en la región latinoamericana y dan algún recurso a las familias con el fin de pedir alguna "contraprestación", por ejemplo, asegurar la asistencia a las escuelas de niños y niñas, además de asistir a revisiones médicas, entre otras condiciones (Chaves y Ramírez, 2006). A partir de 2002 el Progresa se transformó en "Oportunidades" y desde 2014 se denomina "Prospera", manteniendo los componentes de sus antecesores: alimentación, salud y educación. Cuando se denominó Oportunidades extendió su cobertura al nivel medio superior mediante becas para estudiantes y amplió su radio de acción de zonas exclusivamente rurales a zonas urbanas marginadas (Chaves y Ramírez, 2006).

Los programas compensatorios y condicionados, en el caso de la educación, han tenido como objetivo principal elevar la asistencia a la escuela y la permanencia en ella de las/os hijas/os de las familias beneficiarias mediante apoyos económicos y útiles escolares, pero también han supuesto que con la asistencia mejorarían los aprendizajes, cosa que no ha sido demostrada (Martínez, 2012). Las becas se destinan a los/as niños/as y jóvenes de las familias beneficiarias inscritos en grados escolares comprendidos entre tercero de primaria y el NMS.

\footnotetext{
${ }^{4}$ Por ejemplo, Tuirán (2018: 41) registra que hubo un aumento del ciclo 2013/2014, cuando se becó al 2\% de estudiantes hablantes de lengua indígena por el PROBEMS, y para al 2016/2017 fueron 13\%. Para el mismo periodo se apunta que los residentes de zonas de alta y muy alta marginación que fueron beneficiarios de una beca pasaron del $8 \%$ al $23 \%$, pero faltan datos desglosados por sexo para reconocer más detalladamente su impacto.

${ }^{5}$ No es que no hubiese apoyos de ese tipo en el nivel antes, pero eran más inconsistentes o particulares. Por ejemplo, las becas proporcionadas por el Instituto Nacional Indigenista, reportadas en el anexo estadístico del Sexto informe del presidente Zedillo, Disco 21, Tabla 287. Véase http://zedillo.presidencia.gob.mx/welcome/Informes/6toInforme/html/Anexo.htm
} 
El establecimiento de una distribución por sexo fue la principal variable que se introdujo desde que se institucionalizó el programa Oportunidades en el NMS a partir de 2001, pues como se dijo antes dicho programa tuvo como eje focalizar los apoyos en sectores de extrema pobreza; al menos ese fue el énfasis que se reportó en los informes de gobierno, como se observa en la gráfica 9.

De la gráfica se desprende que desde el arranque de este programa de becas en el NMS la mayor cantidad ha sido para las mujeres, a pesar de que generalmente los indicadores del trayecto son desiguales para los varones, como se mostró en el apartado previo. Asimismo, tampoco es claro porqué el programa ha ofrecido montos superiores a las mujeres, incluso entre los tres grados que comprende el citado nivel, como se destaca en los reportes gubernamentales (ver gráfica 10). Tal observación se había señalado en un par de evaluaciones externas realizadas al programa por la Universidad Autónoma Metropolitana (UAM) y el Centro de Investigación y Docencia
Económicas (CIDE), en 2008 y 2010, respectivamente. En ambas se destacaron algunas inconsistencias, entre ellas, problemas en el diseño y que no se justificaba la disparidad de montos: "La diferenciación de ingresos por género no está justificada en las RO", por lo que debía revisarse su validez en relación "con las estadísticas de permanencia en la educación media superior" (UAM, 2008: 7).

Como se desprende de las gráficas 9 y 10 es evidente el sesgo de género, que se explica en parte por cierto malentendido; es decir, se aplica una acción afirmativa hacia las mujeres que no se deriva de los datos. Una posible razón, además de la tasa de absorción, de por qué se ha mantenido el sesgo detectado, es evitar una oleada de críticas del actuar gubernamental, al suponer que dar más becas a los varones se interpretaría como no equitativo. Sin embargo, atender las causas que afectan o impiden la permanencia y la conclusión de los estudios de hombres y mujeres, implicaría estar incluyendo la perspectiva de género, no sólo una política afirmativa para las mujeres (Matarazzo s/f: 27).

Gráfica 9. Distribucion de becas federales (Oportunidades-Prospera) NMS por sexo, 2001-2017

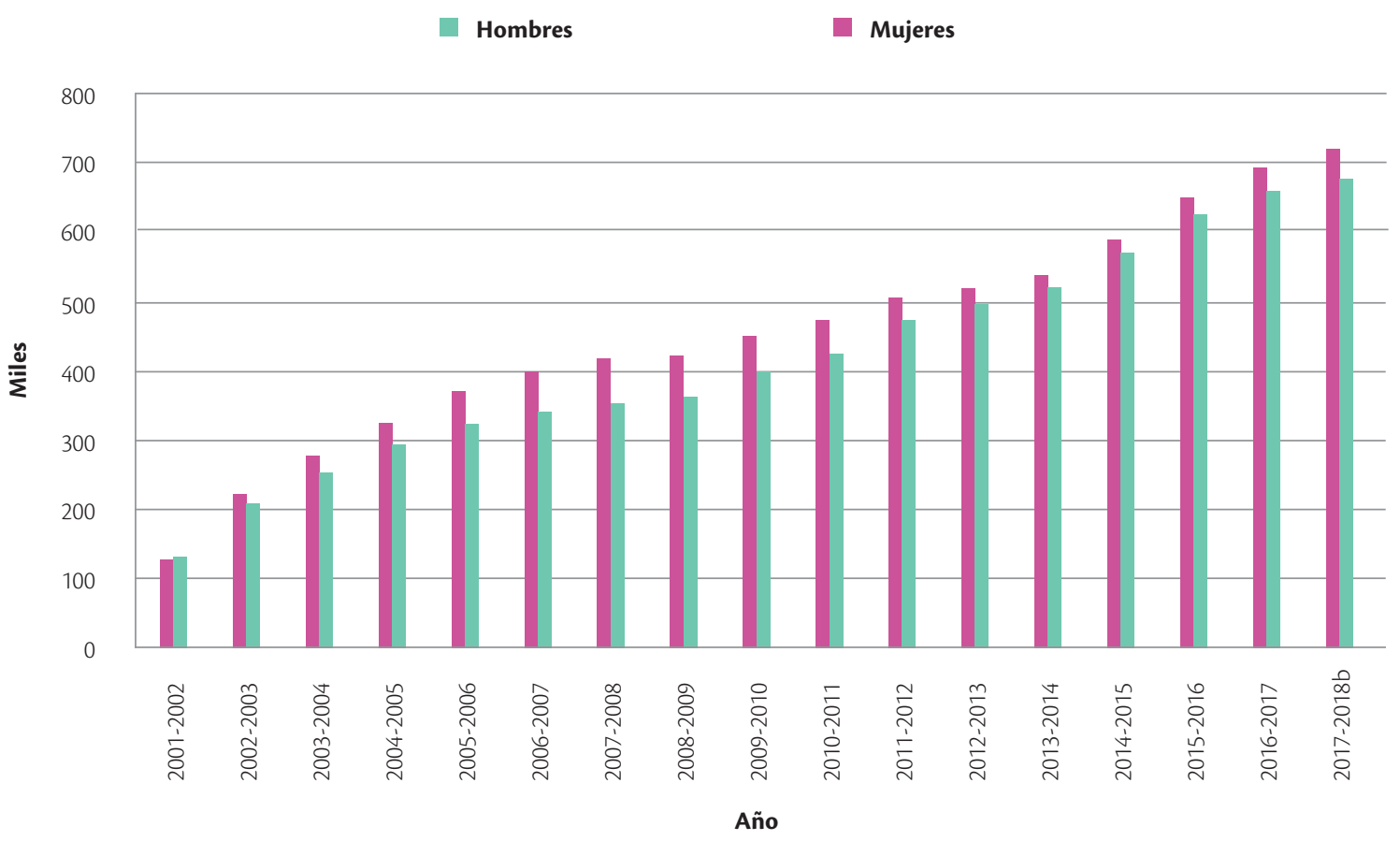




\section{Gráfica 10. Monto mensual de la beca Oportunidades-Prospera NMS, por sexo y por grado 2001-2016}
Primero
Segundo
Tercero

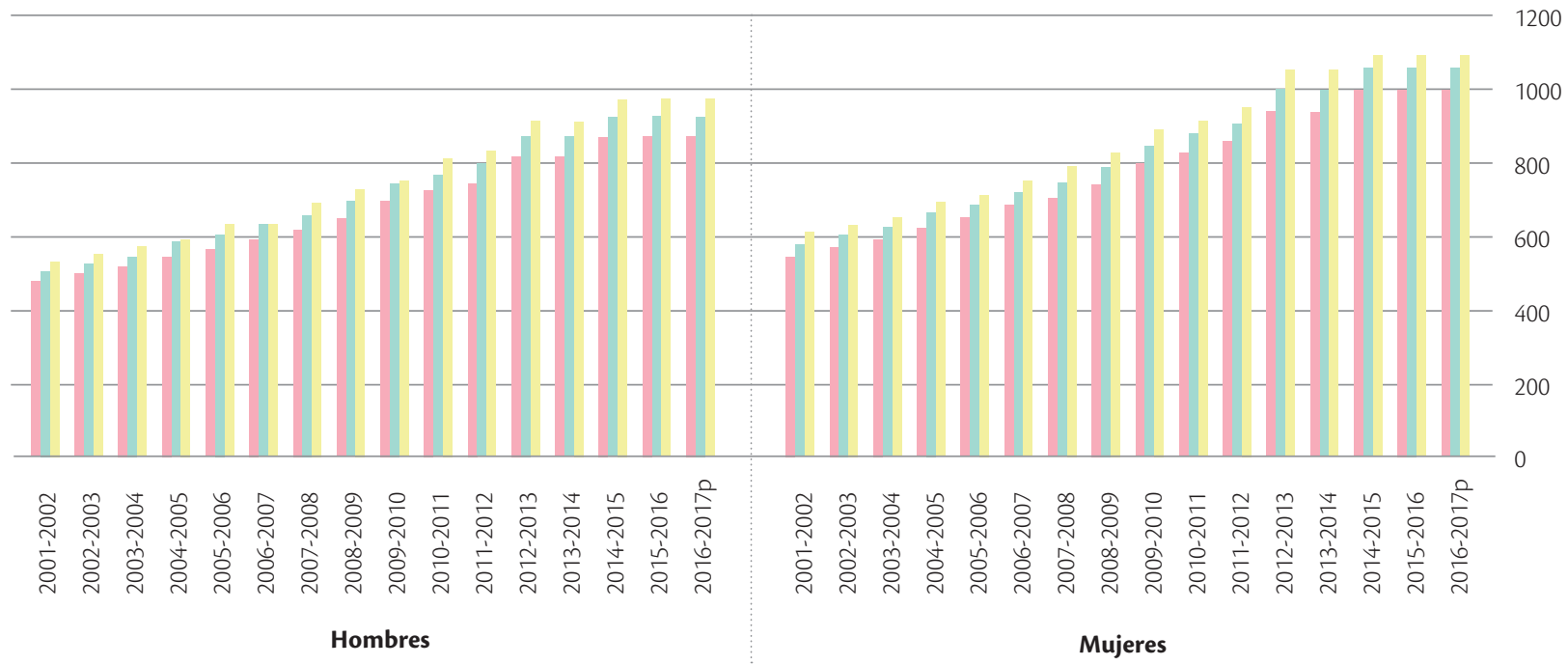

Fuente: Anexo estadístico del $5^{\circ}$ Informe de Gobierno, 2017. $p$ = preliminar

Al programa Oportunidades se le añadió en 2003 un "componente" consistente en una transferencia monetaria como "bono de salida", el cual debía ser cobrado directamente por los/as jóvenes al momento de graduarse del NMS si cumplían con asistencia regular a la escuela y a sesiones de educación para la salud, además de no rebasar los 22 años. Este componente tuvo bajo impacto y se puede considerar complementario de la beca Oportunidades, ya que no añadió otra variable (Troncoso, 2008: 56-58).

Por otra parte, a partir de 2002, se puso en marcha otro programa de becas, enfocado a ofrecer apoyos a la "excelencia y al aprovechamiento escolar", cuyas "reglas de operación" se publicaron en 2003. Desde entonces se han venido adecuando para abrir o cerrar diversos tipos de becas en el NMS. En 2007 la SEP fusionó todas las modalidades de dicho programa, denominándolo como "programa de becas de la educación media superior" (PROBEMS) y reportó de modo sistemático cifras sobre él.
Vale la pena describir con cierto detalle la "identidad" del PROBEMS, debido a que introduce un principio diferenciador en el mecanismo de distribución de becas, el cual se vio mezclado con un principio fuertemente meritocrático que vale la pena discutir. Las reglas de operación (RO) para el año 2003-2004 marcan el paso de ser un programa piloto a su generalización. En sus considerandos se dice que:

es vital que los apoyos gubernamentales en materia educativa se otorguen de manera preferente a los grupos que enfrentan condiciones económicas y sociales de desventaja, pero a la vez, deben también atenderse otros sectores y necesidades del sector educativo, especialmente, aquellos factores de motivación que eviten el bajo rendimiento escolar, fomenten la calidad de la educación y premien la dedicación y el esfuerzo constante de los educandos que acrediten un excelente rendimiento académico (DOF, 2003: 2). 
En la presentación del programa se perfila con más detalle el desplazamiento de la equidad por un énfasis meritocrático:

\begin{abstract}
con una orientación más enfocada a la calidad de los procesos educativos y niveles de aprendizaje, se estimó conveniente en el 2002 reorientar el Programa de Becas en Efectivo para escuelas administradas por la Secretaría de Educación Pública a un Programa de Becas a la Excelencia Académica y al Aprovechamiento Escolar que permita complementar los esfuerzos individuales realizados por los alumnos más destacados y a la vez, no duplicar esfuerzos del Gobierno Federal en objetivos específicos como los trazados por Oportunidades (DOF, 2003: 4).
\end{abstract}

En los objetivos generales se puso de relevancia únicamente el rasgo del "reconocimiento al desempeño académico", dejando de lado el asunto de la necesidad o equidad. Pero en las modalidades en que se dividió el programa vuelve a aparecer el asunto compensatorio: 1) excelencia académica, 2) al talento artístico o deportivo excepcional, 3) aprovechamiento escolar y 4) compensatorias. ${ }^{6}$

Asimismo, cabe destacar que el PROBEMS abarcó instituciones dependientes de la SEP, principalmente bachilleratos tecnológicos federales; luego incorporó instituciones relacionadas con el deporte y la educación artística entre 2004 y 2007 (para justificar especialmente las modalidades de talento), pero también del nivel superior tecnológico. En otras palabras, hasta 2009 se dejaron de lado los bachilleratos generales, tanto los descentralizados como los autónomos (la matrícula nacional más numerosa) y el tipo profesional técnico, sin dar una razón de porqué se excluyeron, por lo que se advierte parcialidad en el tipo de bachilleratos favorecidos y propiamente en los objetivos del programa.

Más aún, entre 2003 y 2016 se han creado (y cerrado) diversas modalidades de becas para atender sectores diferenciados de la población estudiantil (ver cuadro 3). En ello se observan dos movimientos que se conjugan de modo tenso. Por una parte, es marcada la tendencia a ampliar las modalidades; esto es, abrir un abanico al reconocimiento de ciertos grupos vulnerables o vulnerabilizados tales como las personas que viven con alguna discapacidad, afrodescendientes, indígenas, hijos/as de militares, etcétera. Por su parte, a la tendencia previa se agregan apoyos para "emprendedores", beca de idiomas, de movilidad, entre otras; es decir, apoyos que apuntan al reconocimiento de los méritos estudiantiles, que como se sabe suelen recaer en jóvenes de familias de clases medias y altas. En otras palabras, se observa que en el programa coexiste la tensión entre los principios de equidad y mérito.

Los montos de las becas de las distintas modalidades del PROBEMS han variado, siendo las mejor tasadas las de excelencia (aunque fueron pocas destinadas a ello), luego las del talento excepcional y las de aprovechamiento; al final quedaban las compensatorias (véase cuadro 4). Entre 2003 y 2007 se mantuvo el mismo esquema, luego varió, pero manteniendo el énfasis meritocrático con alusiones a la excelencia, el talento excepcional o el emprendimiento.

\footnotetext{
${ }^{6} \mathrm{Al}$ respecto, en un informe de evaluación de dicho programa, en su versión de 2007, se menciona de modo confuso que para entonces se había establecido como meta asignar un 50\% de becas "por necesidad", esto se consideró como "realista atendiendo a que el programa lleva varios años transitando a un programa esencialmente basado en el mérito" (CIESAS, 2007, anexo VII). Sin embargo, se cita que de 2004 a 2007 el porcentaje de becas "por necesidad económica" pasó de 59\% a 54\%.
} 
Cuadro 3. Tipos de becas del PROBEMS, según reglas de operación, 2003-2016

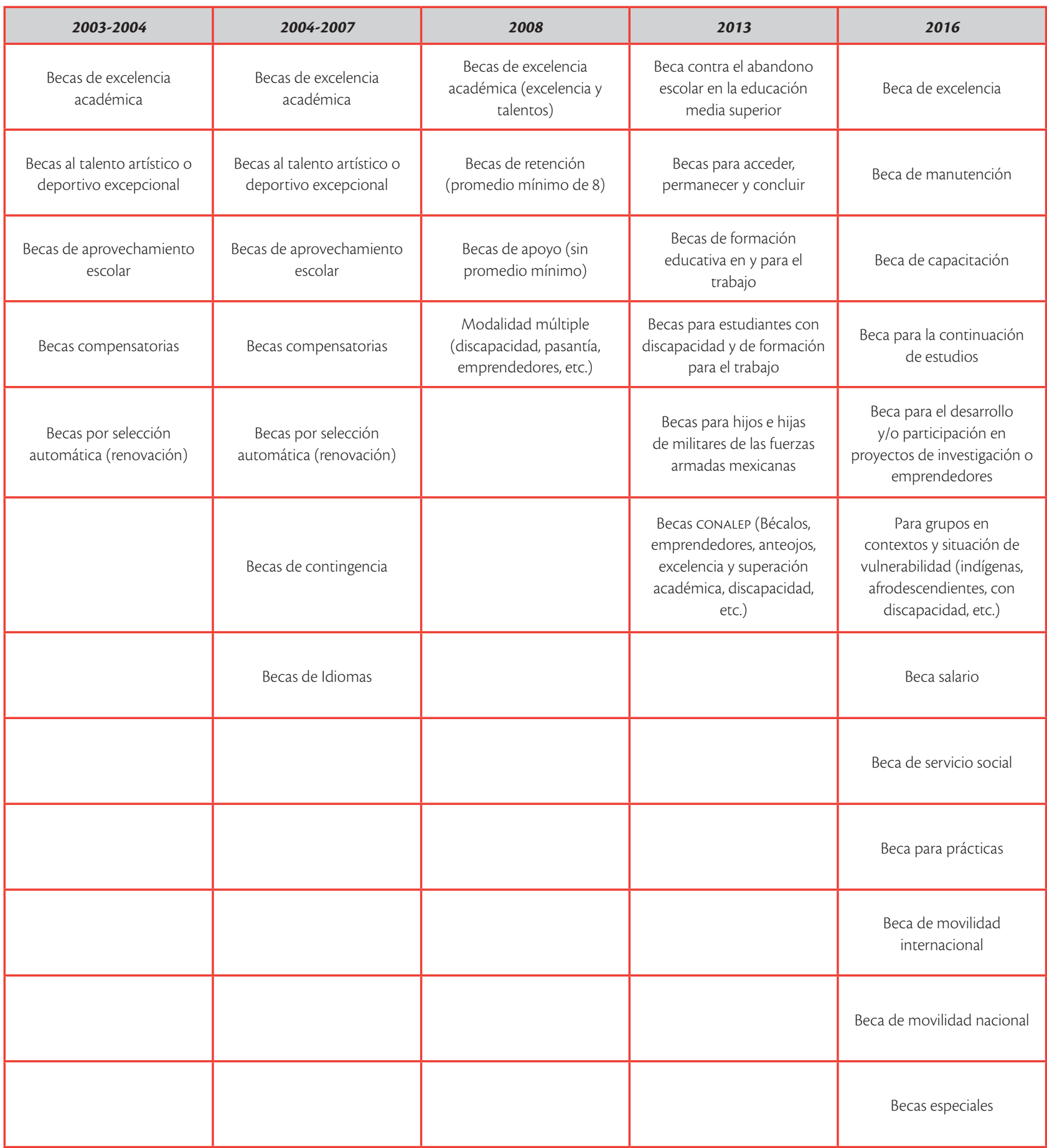

Fuente: Reglas de Operación de los programas de becas del nivel medio superior, varios años 


\section{Cuadro 4. Monto mensual de las becas según tipo y nivel de apoyo,} 2003-2007

\begin{tabular}{|c|c|c|c|}
\hline 2003-2004 & 2004-2005 & $2005-2006$ & $2007-2008$ \\
\hline \multicolumn{4}{|c|}{ Becas de excelencia académica } \\
\hline Nivel III \$3050 & Nivel V \$4 270 & Nivel V \$4 270 & Nivel V \$4 270 \\
\hline Nivel II \$2 440 & Nivel IV \$3 660 & Nivel IV \$3 660 & Nivel IV \$3 660 \\
\hline \multirow[t]{3}{*}{ Nivel I \$1 830} & Nivel III \$3050 & Nivel III \$3 050 & Nivel III \$3050 \\
\hline & Nivel II \$2 440 & Nivel II \$2 440 & Nivel II \$2 440 \\
\hline & Nivel I \$1 830 & Nivel I \$1 830 & Nivel I \$1 830 \\
\hline \multicolumn{4}{|c|}{ Becas al talento artístico o deportivo excepcional } \\
\hline$\$ 1830$ & $\$ 1830$ & $\$ 1830$ & $\$ 1830$ \\
\hline \multicolumn{4}{|c|}{ Becas de aprovechamiento escolar } \\
\hline \multirow[t]{3}{*}{$\$ 610$} & Nivel II \$700 & Nivel III \$1 000 & Nivel III \$1 000 \\
\hline & Nivel I \$660 & Nivel II $\$ 800$ & Nivel II \$800 \\
\hline & & Nivel I \$750 & Nivel I \$750 \\
\hline \multicolumn{4}{|c|}{ Becas compensatorias o de incentivo académico } \\
\hline \multirow[t]{3}{*}{$\$ 610$} & $\$ 610$ & Nivel A $\$ 620$ & Nivel A $\$ 620$ \\
\hline & & Nivel $B \$ 500$ & Nivel B $\$ 500$ \\
\hline & & Nivel C $\$ 750$ & Nivel C \$750 \\
\hline
\end{tabular}

Fuente: Diario Oficial de la Federación, Reglas de Operación del Programa de Becas a la Excelencia y al Aprovechamiento Escolar, ciclos 2003-2004/2007-2008

Precisamente, al ser pocas las becas de excelencia (se otorgaron solo 40 en el ciclo 2004-2005 y 32 en los dos restantes, según Troncoso, 2008) con montos importantes, muy distantes de las compensatorias e incluso de las de aprovechamiento, es evidente que se dio mayor valor al mérito. De este modo, queda en duda que a través de ello se mejoraría la calidad educativa o cómo habrían de servir de motivación, según se manifestó en las reglas de operación para la comunidad estudiantil del NMS, cuando lo que se premiaba era la trayectoria previa e incluso el dominio de un idioma extranjero. Este argumento en cierta medida también es válido para criticar la vertiente ligada al "aprovechamiento", pues generalmente para ser merecedor/a de esta beca había que cumplir con un promedio de mínimo 9, prácticamente desde la primaria. Por lo que la probabilidad de que el alumnado de menores ingresos pudiera obtener una beca de excelencia o aprovechamiento era muy baja.

Por lo tanto, convengo con Troncoso (2008: 63) en que el PROBEMS tuvo problemas en su diseño, al no contar con un diagnóstico riguroso de la situación existente, ni fue consecuente con los planteamientos del diagnóstico educativo del Programa Nacional de Educación del gobierno foxista. Es más, parece que fue un programa que en alguna medida "resistió" o desvirtuó los planteamientos relativos a la justicia y 
la equidad, entendidas con dar más y mejor a los grupos de población que han padecido desigualdades añejas e incrustó el principio meritocrático en el corazón de la política de becas del NMS.

Por su parte, desde 2009 se fusionaron los programas ubicados en varias dependencias para constituir el "programa de becas de la educación media superior", con la idea de unificar los criterios de distribución, quedando clasificadas en tres rubros: modalidad múltiple, retención y excelencia (SEP, 2009). Entonces se modificaron los montos, reduciéndolos a $\$ 500$ el mínimo para la beca de apoyo (para hombres vs $\$ 525$ para mujeres) y $\$ 1000$ como máximo para la de excelencia (que correspondió a las mujeres vs $\$ 950$ para hombres). Los ajustes constantes se han mantenido hasta 2016; es decir, se han creado y cerrado tipos de becas, se redujo la disparidad de montos entre las diversas modalidades, y se sigue reconociendo el mérito, pero la mayor cantidad de apoyos se otorgan para la compensación. En breve, se han realizado ajustes a la política de becas federal, pero siguen las tensiones entre mérito y compensación. Esto a partir de los nuevos planes nacionales de desarrollo y los sectoriales, pero también relacionados con la filosofía del programa y las variables o grupos que se consideran como "población objetivo".

También es interesante revisar que el PROBEMS incluyó la variable de sexo/género. En los primeros años siguió una distribución marcadamente diferencial a favor de las mujeres, especialmente en las modalidades de excelencia y aprovechamiento, como lo reporta Troncoso (2008), entre 2003 y 2006. Un reporte más reciente (Tuirán, 2018), anota los datos relacionados con la "excelencia" entre 2013 a 2017, que son favorables a las mujeres, pero también han bajado considerablemente los apoyos, prácticamente no rebasan los 10 mil (ver gráfica 11).

\section{Gráfica 11. Becas del programa de excelencia y aprovechamiento por sexo, 2003-2006 y 2013-2017}

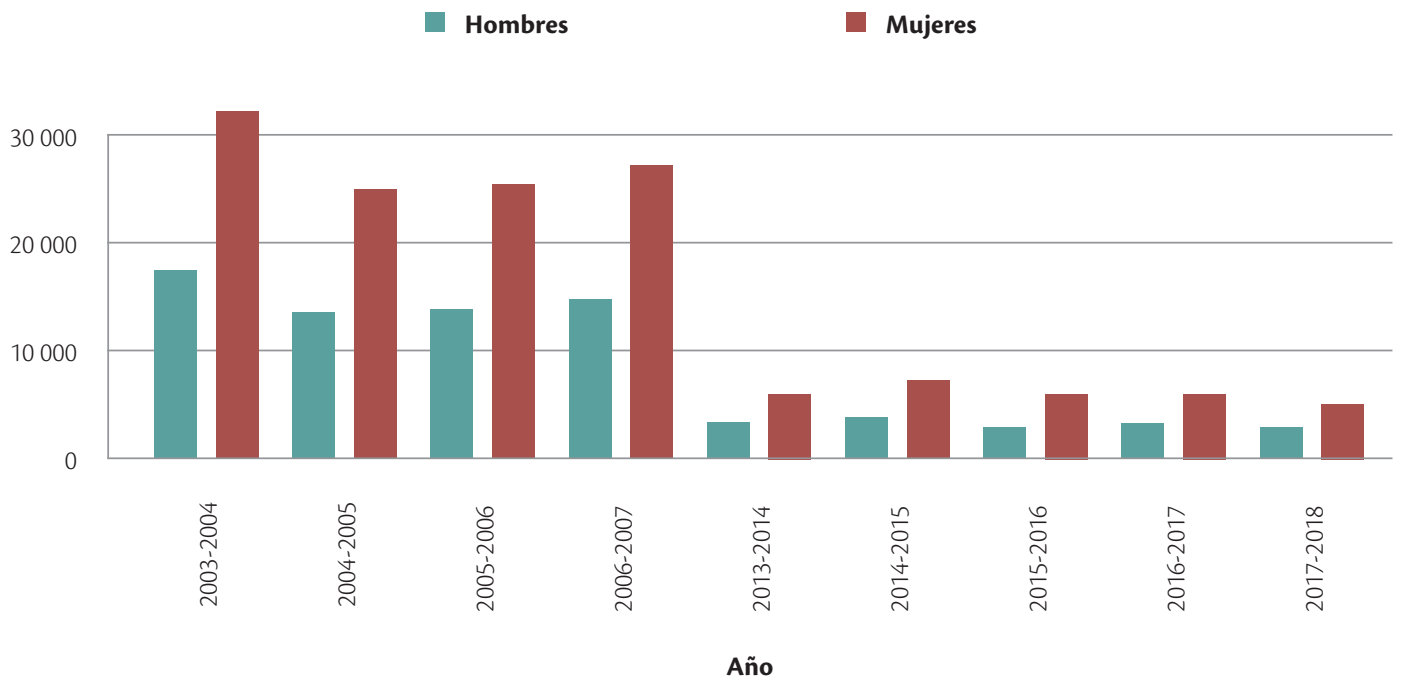

Fuente: Troncoso, 2008: 103 para 2003-2006 y para 2013-2017 Tuirán, 2018: 48 
En este sentido, de acuerdo con Matarazzo, en un incipiente análisis de la distribución de becas del sexenio calderonista (2006-2012), en modalidades del NMS como "Retención de estudiantes", "Apoyo a estudiantes en educación media superior" y "Becas de excelencia", en las reglas de operación "no se establece que haya prioridad para seleccionar mujeres sobre hombres o que se asignará un mayor número de becas a mujeres que a hombres" (Matarazzo, s.f.: 26).

Recientemente se realizaron nuevos arreglos que señalan un cambio a favor de un enfoque de género durante el trayecto escolar de los y las jóvenes en el NMS, es decir, se ha perfilado sumar el sexo con otros criterios para el otorgamiento de becas, como se puede ver en el cuadro 5. Para el ciclo 2015/2016 se destaca que si bien se otorgan más becas a mujeres, el porcentaje de la modalidad "abandono" es mayor para los varones; asimismo, es comprensible y en congruencia con los datos que se otorguen más becas a ellas que a ellos en la modalidad de "continuidad", ya que implica apoyos al ingreso y a la permanencia. Aunque no queda explícito porqué son más becas en total para las mujeres ni para el rubro de permanencia, ni porqué a ellos les otorguen más becas en la modalidad "transporte", por lo que se puede decir que la política ha seguido una tendencia errática y friccionada, que por momentos parece sesgarse al hacer equivalente la equidad de género como apoyo exclusivamente a las mujeres, pero en otros parece que la distribución es realizada de modo arbitrario, sin fundamento en los datos disponibles, ni principios claros.

Sin embargo, los ajustes recientes apuntan hacia cierto reconocimiento de las diferencias del estudiantado en sus trayectos escolares y contextos, así como de condiciones como el sexo, etnia y lugar de residencia, entre otras, que deben seguir conjugándose para diseñar e instrumentar una política de becas más justa.

Finalmente, cabe señalar que las becas PROBEMS aumentaron de modo significativo en los últimos cuatro años (alcanzaron el 45\% en 2013), y con ello, la presencia del elemento meritocrático, el cual convive tensamente con el principio compensatorio característico del programa Prospera (véase la gráfica 12).

Cuadro 5. Porcentaje de becas PROBEMS otorgadas por modalidad y género 2015-2016

\begin{tabular}{|c|c|c|c|c|c|}
\hline & Abandono escolar & Continuidad & Transporte & Otras & Total de becas \\
\hline Hombres & 52.2 & 30.6 & 3.6 & 13.6 & 274,749 \\
\hline Mujeres & 49.5 & 33.6 & 3.1 & 13.8 & 326,046 \\
\hline
\end{tabular}

Fuente: https://www.becasmediasuperior.sep.gob.mx/estadistica\# 


\section{Gráfica 12. Becas NMS PROBEMS y Oportunidades-Prospera, 2007/2008-2016/2017}

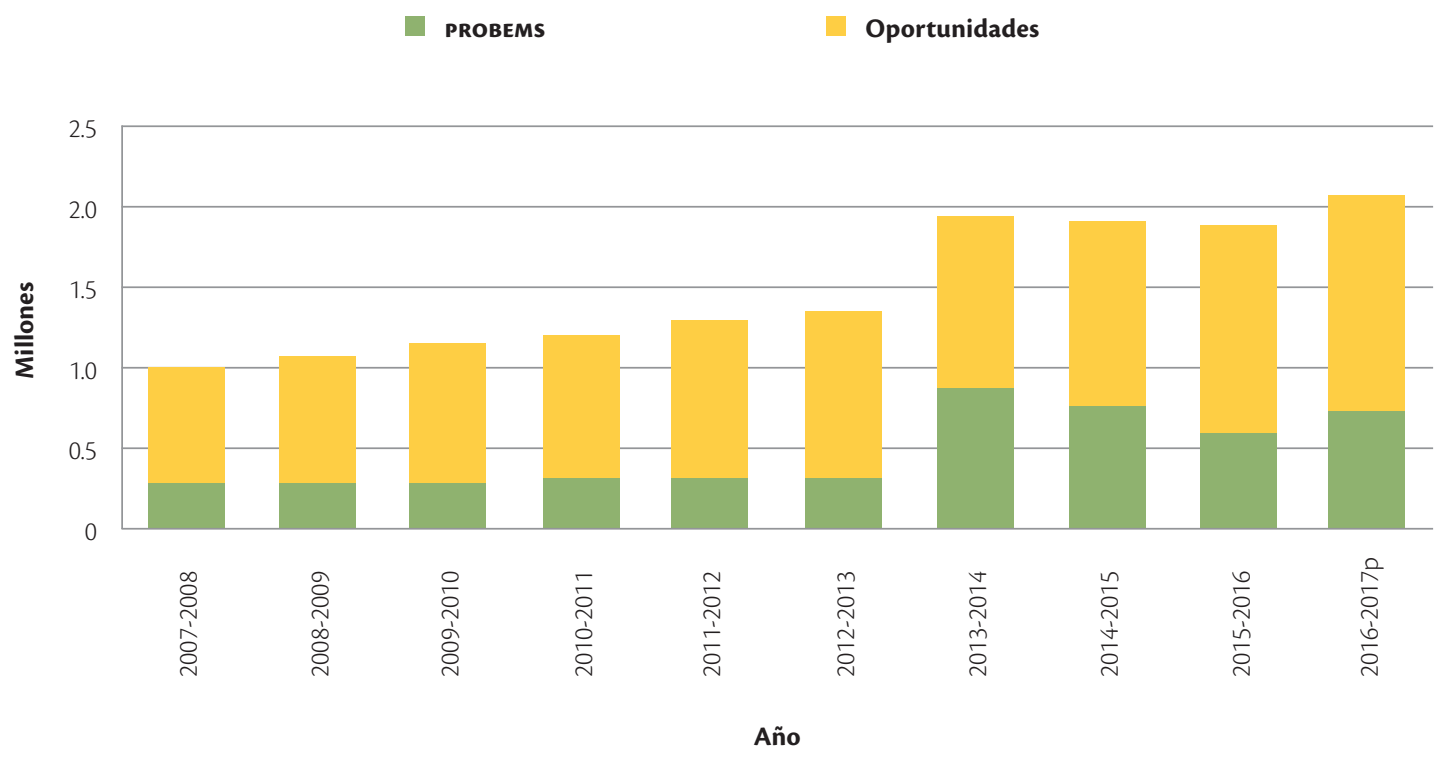

Fuente: Informes de labores SEP, 2012, 2013 y 2017. $p=$ preliminar

\section{Consideraciones de cierre}

En este trabajo se mostró que el diseño de la política de becas del NMS ha estado atravesado por cierto sesgo de género y por principios en tensión, ya que mezclan propósitos compensatorios con meritocráticos, por lo que describimos inconsistencias entre tales premisas y la efectiva distribución de apoyos a lo largo de poco más de tres lustros.

En relación con el principio de distribución de becas, el diseño de los programas federales ha funcionado de modo errático, mediante un principio estrecho y contradictorio. Es estrecho porque se ha guiado mayormente por una "distribución de mínimos", escasamente redistributivo, y a la vez por una marcada lógica individual. Y es contradictorio porque la instrumentación, por una parte, promueve las becas como un incentivo al esfuerzo individual (las compensatorias), y por otra, como un premio a la trayectoria y mérito personal (las de excelencia). De ese modo, prevalece una visión liberal y no una de derechos, pues en este último caso la asignación se entiende como restitución de un derecho vulnerado ante la falta de condiciones sociales para acceder a la educación, que no implica acreditar algún mérito. A pesar de las críticas hechas por evaluaciones externas, no se ha profundizado en cuestionar la organización ni los métodos más justos para la toma de decisiones de la instancia gubernamental que distribuye las becas; algo cercano a lo que Young (2000: 43), llama las "condiciones estructurales e institucionales específicas" de la justicia, donde se define no sólo qué se distribuye, sino cómo y quién lo hace.

Además, la beca es un paliativo porque en términos generales no cubre los costos directos de la escolaridad y el costo de oportunidad en los/as jóvenes. Por tal motivo se requieren estudios para conocer los montos óptimos que incidan efectivamente en la permanencia de los/las jóvenes. Como ha señalado un estudio amparado por el Banco Mundial (BM, 2013: 46): "es evidente que los programas de becas, incluido el Programa Oportunidades, no son suficientes para contrarrestar las necesidades y los bajos ingresos de los hogares". Esto es significativo, ya que como señalan los datos de la Encuesta Nacional de 
Deserción Escolar (SEMS y COPEMS, 2012), los factores económicos siguen siendo determinantes para $36.4 \%$ de los/as jóvenes que dejan la escuela (incluso en ese rubro los varones presentan mayor desigualdad: $39.1 \%$ vs $33.7 \%$ de las mujeres), que suele hacer sinergia con otras variables tales como la maternidad, la zona de residencia, el desinterés por la escuela o los contenidos escolares, etcétera.

Podemos concluir que se ha venido trabajando en el reconocimiento de las identidades (hijos/as de militares, jóvenes embarazadas, indígenas, etcétera), pero no se combina con una mayor distribución de recursos para, por ejemplo, chicas indígenas o de jóvenes de poblaciones alejadas de los centros urbanos y pobres; en ambos casos, diferenciando su trayecto. En breve, no se hace el cruce de condiciones socioeconómicas pobres, lugar de residencia y/o pertenencia étnica, entre otras, de las poblaciones más vulnerables. Por ello no se atacan de modo integral tales desigualdades y se tienen pocas probabilidades de éxito en combatirlas (Messina, 2001; BM, 2013).

Por su parte, el género en la política gubernamental de becas necesita pensarse combinando la redistribución con el reconocimiento de las diferencias, así como el marco de distribución. En este sentido, queda en entredicho el objetivo de favorecer la equidad de género, pues hasta ahora no es explícita la justificación de disparidades entre unos y otras en la distribución de las becas y sobre todo en los montos, por lo que se puede decir que sólo se ha seguido una política de afirmación positiva para las mujeres.

En todo caso, teórica y prácticamente, afrontar la injusticia de género exige cambiar tanto estructuras económicas como el orden de estatus (Fraser, 2008: 93). En ese sentido, se hace necesario impulsar una discusión de los principios que guíen la distribución justa de becas en el NMS, que combinen rigurosamente la construcción de un marco democrático y el reconocimiento de las diferencias y desigualdades de grupos, contextos y trayectorias que responda óptimamente a las necesidades de poblaciones diversas y desiguales. Algo se ha intentado en los últimos dos años con las becas de reingreso, de permanencia, de servicio social, de formación dual, etcétera. Pero se deben construir políticas más integrales de modo sostenido en el tiempo, dando prioridad a los grupos más necesitados durante el trayecto escolar, considerando su representación paritaria en las RO, y con ello, pasar de un enfoque basado exclusivamente en un modelo distributivo a uno de derechos que considere cuestiones de procedimientos institucionales y la toma de decisiones democráticas como parte sustantiva de la justicia escolar y/o educativa (Young, 2000).

También deben considerarse los efectos encadenados al desarrollo de los ciclos de vida de mujeres y varones, durante los cuales las desigualdades se mantienen y, en la mayoría de los casos, se profundizan (Feijoó, 2013: 12). De hecho, algunos datos alertan sobre el descuido de las desigualdades de género que afectan a los varones. Como acertadamente lo señala el informe reciente de la UNESGO (2015: 199) sobre la Educación para Todos: "Se necesitan políticas distintas para las niñas y para los varones a fin de apoyar la matriculación y la finalización escolar de unas y otros". Más aún, existen otros espacios escolares y recursos en los cuales se debe ir trabajando para incluir la perspectiva de género, tales como los contenidos, los libros de textos y en la formación de los docentes. Por ello es necesario diseñar políticas integrales considerando los diferentes elementos que obstaculizan la inscripción, la permanencia, la conclusión de los estudios, así como la construcción de aprendizajes significativos para las/los jóvenes (Matarazzo, s. f.: 36).

En conclusión, podemos afirmar que la política educativa de distribución de becas en el NMS no es solamente una cuestión de medidas técnicas, sino consecuencia de los principios de justicia elegidos por el sector que gobierna, por lo tanto, la concepción de justicia que se instrumente en el proceso de gobernanza debe ser adecuada, consecuente y efectiva, en 
este caso orientada por una perspectiva de género. Debe partirse entonces de una concepción más compleja que reconozca las diferencias y desigualdades de los grupos y sus contextos, priorizando a quienes

\section{Referencias}

Banco Mundial (BM) (2013), Después de la educación media superior: un análisis para el Estado de Oaxaca, México, BM.

Barajas, Gabriela (2006), “¿Es Oportunidades un programa con un presupuesto pro-equidad de género?", El Cotidiano, vol. 21, núm. 139, pp. 50-59.

Bourdieu, Pierre (2000), La dominación masculina, Barcelona, Anagrama.

Chaves, Patricio y Rodolfo Ramírez (2006), Análisis crítico de las evaluaciones de los programas compensatorios, 19942004, México, CONAFE.

CIDE (2010), Evaluación de diseño del Programa Federal "Programa de Becas". Informe final, México, CIDE.

Cuellar, Daniel (2013), "Pertinencia en el diseño y primeros resultados del programa de becas de educación media superior (PROBEMS). Una revisión desde el análisis de políticas", Ponencia presentada al XII Congreso nacional de investigación educativa, Guanajuato, 18 al 22 de noviembre.

De Barbieri, Teresita M. (1995), "Certezas y malos entendidos sobre la categoría de género", en Estudios básicos sobre derechos humanos, vol. IV, San José, Instituto Interamericano de Derechos Humanos.

DOF (2003), "Reglas de Operación del Programa Nacional de Becas a la Excelencia Académica y al Aprovechamiento Escolar aplicables al ciclo 2003-2004 (25 de abril)", <http://dof.gob.mx/nota_detalle.ph p? codigo $=697927 \&$ fecha $=25 / 04 / 2003>\quad$ [Consulta: mayo 2017].

DOF (1999), "Acuerdo que establece los Lineamientos Generales para la Operación del Programa de Educación, Salud y Alimentación (Progresa). (26 de febrero)", <http://www.dof.gob.mx/nota_detalle.php?codigo $=494$ 4430\&fecha $=26 / 02 / 1999>$ [Consulta: agosto 2018]. más necesitan, pero también cuándo y dónde más lo necesitan, instrumentando las medidas suficientes para mejorar las oportunidades y la vida de las y los jóvenes.

Fraser, Nancy (2008), "La justicia social en la era de la política de la identidad: Redistribución, reconocimiento y participación", Revista de trabajo, vol. 4, núm. 6, pp. 83-99.

Feijoó, María del Carmen (2013), "Educación y equidad de género", LASA Forum, vol. XLIV, núm. 2, pp. 12-14.

Lamas, Martha (comp.) (1996), El género: La construcción cultural de la diferencia sexual, México, PUEG-UNAM/ Miguel A. Porrúa.

Martínez, Eduardo y Roberto Martínez (2013), "Análisis del efecto de las becas económicas en el rendimiento escolar en una institución de nivel medio superior", Investigación y Ciencia de la Universidad Autónoma de Aguascalientes, núm. 59, pp. 40-46.

Martínez, Oscar (2012), "Efectos de las becas educativas del programa Oportunidades sobre la asistencia escolar. El caso de la zona urbana del noreste de México", Desarrollo y Sociedad, núm. 69, pp. 99-131.

Matarazzo, María C. (s.f.), "La igualdad entre mujeres y hombres en el ámbito educativo nacional. Análisis de las acciones implementadas por la Secretaría de Educación Pública en materia de igualdad entre mujeres y hombres", <http://www.cndh.org.mx/sites/all/doc/ programas/mujer/9_Investigaciones/9.1/9.1.pdf> [Consulta: noviembre 2017].

Messina, Graciela (2001), "Estado del arte de la igualdad de género en la educación básica de América Latina (1990-2000)", Igualdad de género en la educación básica de América Latina y el Caribe, Santiago, OREALC-UNESCO, pp. 11-43.

Murillo, FranciscoJ., Marcela Román y Reyes Hernández (2011), "Evaluación educativa para la justicia social", Revista Iberoamericana de Evaluación Educativa, vol. 4, núm. 1, pp. 7-23. 
OCDE (2017), Building an inclusive Mexico, policies and good governance for gender equality, París, OCDE.

Ordorika, Imanol (2015), "Equidad de género en la educación superior", Revista de la Educación Superior, vol. 44, núm. 174, pp. 7-17.

Presidencia de la República (2018), 6to Informe de gobierno 2017-2018, México, Gobierno de los Estados Unidos Mexicanos, <http://www.presidencia.gob. $\mathrm{mx} /$ sextoinforme/> [Consulta: septiembre 2018].

Programa de Educación, Saludy Alimentación (Progresa) (1998), <https://www.gob.mx/cms/uploads/attachment/ file/79893/1998--.pdf> [Consulta: agosto 2018].

SEMS y COPEEMS (2012), Reporte de la Encuesta Nacional de Deserción en la Educación Media Superior, México, SEMS y COPEEMS.

SEP (2013), Programa Sectorial de Educación 2013-2018, México, SEP.

SEP (2009), Tercer informe trimestral programa becas de educación media superior 2009, México, SEMS-DGETI.
Troncoso, Emery (2008), "Políticas en materia de equidad en el nivel medio superior, análisis del sexenio 20002006 en México", Tesis de Maestría en Gobierno y Asuntos Públicos, México, FLACsO.

Tuirán, Rodolfo (2018), Avances en la educación media superior, 2012-2017, México, SEP.

UAM (2008), Evaluación de diseño del Programa Nacional de Becas de Apoyo a Estudiantes de Educación Media Superior. Informe final, México, UAM.

UNESCO (2015), La Educación para Todos, 2000-2015: logros y desafios, París, UNESCO.

UNICEF (2017), Informe Anual. México 2017, México, UNICEF.

UNICEF (2015), Informe sobre la equidad del gasto público en la infancia y la adolescencia en México, México, UNICEF/ PNUD.

Young, Iris M. (2000), La justicia y la política de la diferencia, España, Cátedra/Universitat de Valencia/Instituto de la Mujer.

\section{Cómo citar este artículo:}

Aguilar Nery, Jesús (2019), "Política de becas en el nivel medio superior mexicano: crítica a sus principios distributivos", en Revista Iberoamericana de Educación Superior (RIES), México, UNAM-IISUE/Universia, vol. x, Núm. 27, pp. 42-65, DOI: https://doi.org/10.22201/ iisue.20072872e.2019.29.522 [consulta: fecha de última consulta]. 